\title{
Legal Theories and Judicial Decision-Making: An Ontological Analysis
}

\author{
Cristine GRIFFO $^{\mathrm{a}, 1}$, João Paulo A. ALMEIDA ${ }^{\mathrm{b}}$ and Giancarlo GUIZZARDI ${ }^{\mathrm{a}}$ \\ ${ }^{a}$ Free University of Bozen-Bolzano, Italy \\ ${ }^{\mathrm{b}}$ Federal University of Espírito Santo, Ufes, Brazil
}

\begin{abstract}
In this paper, we expose the legal theories underlying two important classes of Legal Core Ontologies and show how these ontologies inherit both limitations and benefits (such as explanatory power) of their underlying theories. We do that with the help of a real case study in which we have normative omission and collision of principles. We use this case study to conduct an ontological analysis of the support for judicial decision-making in LKIF-Core (representing Kelsen's Pure Theory of the Law) and UFO-L (representing Robert Alexy's Theory of Constitutional Rights). We show that UFO-L is able to articulate the semantics of the content of judicial decisions by making explicit the individual's legal positions that are raised in argumentation along a legal process. The same cannot be said of LKIFCore that is based on the Kelsenian stance and focuses on the representation of general norms (norm types) and subsumption of facts to these norms.
\end{abstract}

Keywords. Legal Theory, Judicial Decision-Making, Legal Core Ontologies, LKIF-Core, UFO-L

\section{Introduction}

Judicial Decision-Making refers to the decision-making process through which judges make legal decisions. These are critical processes given that their outcome can substantially affect the lives of legal agents under a jurisdiction (e.g., people, organizations, countries, and collections thereof).

As shown in [1], there is evidence that the outcome of a judicial decision depends among other factors on the philosophical stance underlying the legal theories informing the decision maker. One of the most common of these stances is Hans Kelsen's philosophy of Legal Positivism (also known as Kelsenism or Pure Legal Theory). Under this view, all we have are the legal norms and decision making is, therefore, reduced to a process of subsuming legal facts to these legal norms that constitute a normative system. However, in practice, there are many practical cases in which we have normative omissions (e.g., there are no rules under which a fact can be subsumed). In these cases, legal positivism is unable to offer informative (i.e., non-trivial) insights.

\footnotetext{
${ }^{1}$ Corresponding Author: Free University of Bolzano, Piazza Domenicani 3, Bolzano, BZ, 39100, Italy; Email: cristine.griffo@unibz.it.
} 
In philosophy of law, there are alternative stances that provide a theoretical support for dealing with such cases. A prominent one is Robert Alexy's Theory of Constitutional Rights. Alexy's theory is a relational theory, which by making explicit the legal roles and positions constituting legal relations provide mechanisms for reasoning about the different perspectives of different legal relata involved in specific cases, thus, providing informative guidance for legal operators. For a number of years, the so-called core ontologies have been used to support different tasks in Legal Informatics, including, representing the results of judicial decision-making. However, as discussed in [2], most legal core ontologies follow a Kelsenian stance. A representative example of this Kelsenian class is LKIF-Core [3]. An exception to this trend is the UFO-L core ontology [4].

In this paper, we demonstrate how these different legal theories underlying existing core ontologies influence their ability to articulate the results of Judicial DecisionMaking. We do that with the help of a real judicial case exemplifying a case of normative omission. In this case, the legal norm-rule, that regulates the granting of leave of absence for dealing with private affairs (LDPA) for public servants, foresees specifically two hypotheses: if one is a stable servant, then they are entitled to the leave; if they are not a stable servant, then they are not entitled to the leave. However, the appeal and subsequent decisions in the court of appeals do not simply apply subsumption based on these two hypotheses. Instead, they invoke a collision of norm-principles to establish additional hypotheses not considered in the posited norm-rule. This is a case that received opposite decisions by different decision-makers of the case.

We illustrate how a representative Kelsenian Ontology (LKIF-Core) can be used to represent the decision-making process of the first judge of the case, and how it fails to provide informative insights about the specifics of the case. Then, we employ the UFO-L to fully represent the decision-making process of the second judge, which explicitly follows the principles of Alexy's theory. This analysis demonstrates the ability of UFO-L to: (i) support and explicitly represent the steps involved in an Alexyan decision-making process; (ii) provide informative insights about these cases falling outside a more traditional Kelsenian view. In the ontological analysis made, we verified that, because of the adopted stance (legal positivism), LKIF focuses instead on the content of general and abstract norms (and is not concerned with the legal positions of agents involved in adjudication). Thus, there is in principle a difference on the phenomena that LKIF and UFO-L address. In addition to that, there is no support for principles in LKIF, which are important to many current cases of judicial reasoning (in particular those involved in the so-called "hard cases"). LKIF only supports rules that classify situations into either mandated and prohibited (through subsumption). We demonstrate in this paper that UFO-L is able to articulate the semantics of the content of judicial decisions by making explicit the various legal perspectives that are raised in argumentation along a legal process.

The remainder of this paper is organized as follows. In Section 1, we briefly present the Logical Positivism of Hans Kelsen, the core ontology LKIF-Core, and show how the former has influenced the design of latter. Mutatis Mutandis, we do the same for Robert Alexy's Theory of Constitutional Rights and UFO-L, thus, showing how the latter is an ontological representation of the former. In Section 2, we describe our case study. In Sections 3 and 4, we then employ each of these two ontologies to represent and explicate the decision-making processes of the judges of the case. In particular, in Section 4, we show the notable difference in insight and details supported by UFO-L in contrast to LKIF. In Section 5, we present our final considerations. 


\section{Background}

For many years, ontologies at different levels of generality have been employed to support conceptual modeling and knowledge representation in the legal domain. In a previous paper [2], we present a systematic mapping of the literature on legal ontologies. The term Legal Core Ontology ${ }^{2}$ was introduced in the mid-1990s by [7] to define the class of ontologies that establish relevant categories used in law and reflect the main reasoning structure in this field. These ontologies propose the representation of general concepts of law (e.g. legal relation, legal norm) that can be used in many sub domains (e.g. Criminal Law, Civil Law, Constitutional Law). Of the several legal core ontologies reviewed in [2], we highlight the following: Frame-Based Ontology (FBO) [8], Functional Ontology of Law (FOL) [9], Legal Top Ontology [10], Core Legal Ontology (CLO) [11], LKIFcore [12], and the UFO-based ontology of legal relations named UFO-L [4]. Most of the core ontologies are based on Kelsen's theory. A prominent example is LKIF-Core [13]. An exception to this trend is UFO-L, which is based on Alexy's Theory of Constitutional Rights. In the next two subsections, respectively, we present Kelsen's theory and its reflection in LKIF-Core (which we select here as representative of the positivist stance), and Alexy's theory as represented in UFO-L.

\subsection{Kelsenism and LKIF-Core}

In his work Pure Theory of Law [14], published at the beginning of the 20th century, Kelsen proposes to conceive the law as "a matter of what has been posited (ordered, decided, practiced, tolerated, etc.)" [15] downplaying considerations of political and moral merit. A law in this setting has the form of a conditional order to apply sanctions if a certain prohibited behavior is performed. A legal norm for Kelsen is then formulated as a hypothetical proposition, following the formula: if $A$, then must be $S$, where $A$ is hypothetical conduct and $S$ is the sanction that follows the occurrence of hypothesis.

An ontology based on the Kelsenian view has as its ontological commitment to define law as a system of relations between general norms (norm types) given a priori. Another important point is the subsumption operation that legally typifies the facts. For example, "Joseph stole John's vehicle" becomes legally relevant when an abstract norm type is found ${ }^{3}$ under which this fact can be classified. By subsuming the fact to the norm, the consequence is asserted, that is, a type of sanction for that typified fact is entailed.

The LKIF-Core is a legal core ontology that is part of the Legal Knowledge Interchange Format (LKIF) initiative. LKIF is meant to: enable the translation between legal knowledge bases written in different representations; be a formalism to automate legal reasoning; represent a fragment of LKIF-Core.

Being a typical example of Kelsenian ontology, LKIF-Core [3] has as central notions legal norms and legal facts (represented by the notion of qualified situations or cases,

\footnotetext{
${ }^{2}$ In this paper, "legal ontology" is the kind of which "legal core ontology" is a subkind. However, in literature, the term "legal ontologies" is applied to any legal ontology class. In fact, several studies proposing domain ontologies, application ontologies and core ontologies use the generic term "legal ontology" rather than a more specific term. For example, both the Legal Taxonomy Syllabus tool [5], proposed for the building of legal ontologies, and the OPJK ontology proposed by [6] for legal knowledge representation are presented in the literature as "legal ontologies".

${ }^{3}$ as is the case for Article 155 of the Brazilian Penal Code: "To subtract, for their own benefit or of other's, someone's movable assets. Sanction (...)" [16]
} 
see Figure 1). These are related by the aforementioned subsumption mechanism depicted schematically in Figure 2). As explained in [13]: a norm applies to (or qualifies) a certain generic situation (the qualified situation). It allows certain cases and disallows others. The obliged and prohibited cases are both subsumed by the situation to which the norm applies. These, by definition, form a complete partition of the case to which the norm applies. In LKIF-core, legal norms are classified as: Permission, Prohibition, Obligation and Rights and the legal facts are subsumed to them.

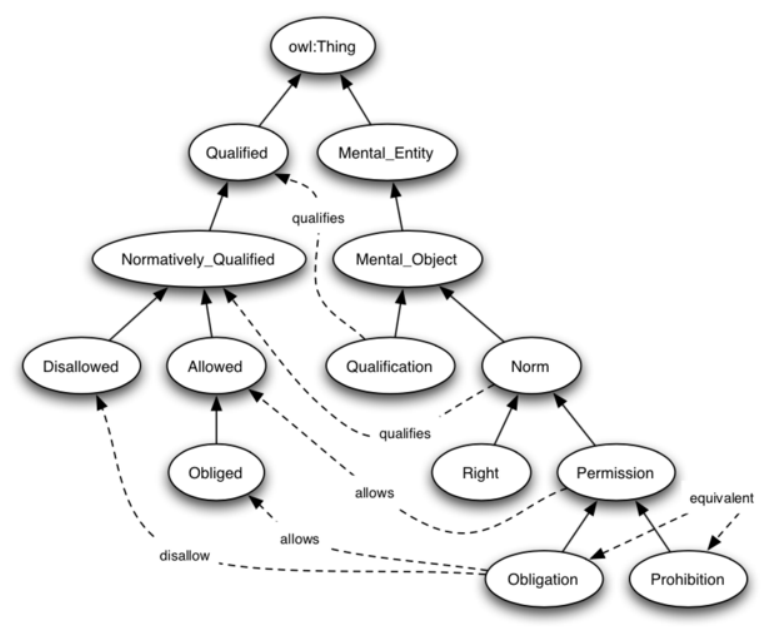

Figure 1. A fragment of LKIF-core representing Qualifications and Norms (from [13])

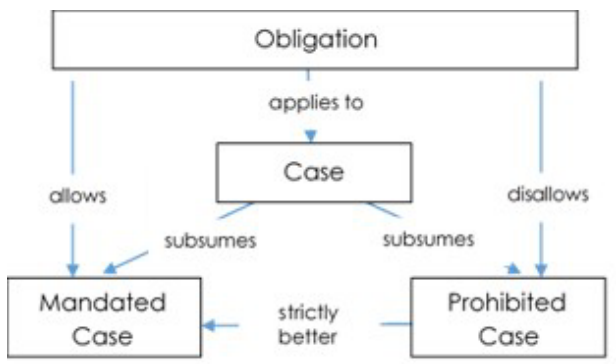

Figure 2. Subsumption structure in LKIF-core ontology (from [17])

\subsection{Alexy's Theory and UFO-L}

The Theory of Constitutional Rights (henceforth TCR) proposed by Robert Alexy [18] is a subjective theory of the law, in the sense that instead of focus on general relations between norms as universals, it contemplates legal relations that are manifested as relationships among individuals (subjects) in concrete specific situations. The context of TCR is the so-called Substantive Law, which is a branch of the Law that creates and 
regulates existing legal dispositions (e.g. rights, duties, liberties, permissions, powers) between individuals.

In a series of papers $[4,19,20]$, we have proposed UFO-L, a core ontology of legal relations grounded in the Unified Foundational Ontology (UFO) [21]. UFO is a formal ontology composed of three parts: UFO-A, which is an ontology of endurants [22]; UFO$\mathrm{B}$, which is an ontology of perdurants [23]; and UFO-C, which is an ontology of social and intentional entities. UFO-L explicitly represents and articulates TCR in terms of the ontological theory of relations proposed by Guarino and Guizzardi [24] (which is a constituent micro-theory of UFO-A), and by reusing from UFO-B and UFO-C.

UFO is a Four-Category ontology that is, thus, organized around the so-called Aristotelian Square. In other words, it is an ontology that contemplates individuals and universals, having both (independent) substantial individuals (and substantial universals), as well as (existentially dependent) moment individuals (and moment universals). Moments can be intrinsically dependent (i.e., qualities, modes) or dependent on multiple individuals (i.e. relators) thus, binding them. Universals are further specialized into kinds of things, roles played by things of a given kind, role mixins representing role-like dispersive properties played by things of multiple kinds, among others.

UFO-L (whose fragment is depicted in Figure 3) extends the basic categories of UFO, prescribing the general notion of Legal Thing, i.e., an individual or universal that is defined in a Legal Normative Description (itself a type of legal individual). Legal individuals are specialized in Legal Events, Legal Substantials (Legal Objects, including Legal Norms and Legal Normative Descriptions, and Legal Agents), and Legal Moments. The latter is further specialized into Legal Relators, which are constituted by Legal Positions such as individualized rights, powers, liberties, subjections, etc [20]. Legal positions are modes and, hence, are existentially dependent on specific individuals. Based on Alexy's theory, Right is a legal position type having as subtypes: Right to an Action; Right to an Omission. In turn, Liberty (another legal position type) has as subtypes: Unprotected Liberty; and Protected Liberty. In UFO-L, a legal position has a relational nature (i.e., it is an externally dependent mode) and, thus, it exists in the scope of a reified legal relation (Legal Relator). Legal relations are bonds between Legal Agents, who then play Legal Roles in their scope. Legal Roles (which specialize the general notion of anti-rigid relational sortals in UFO) are prescribed by Legal Norms. Legal Norm is further specialized in Rule and Principle.

As discussed in depth in [25], UFO-L is organized in terms of a number of Ontology Design Patterns that extend the basic relator pattern proposed in [21]. In the sequel, we present one of these patterns, which will be instrumental to our analysis in Section 4. This pattern, termed the Right-Duty to an Action Legal Relator (P1-RDA-LR) [26] is depicted in Figure 4. As shown in this model, a Right-Duty to an Action is established between a Right Holder and a Duty Holder. The Legal Relator is composed of a pair of counterpart legal positions: a Right to an Action inhering in a Right Holder and externally dependent of a Duty Holder; and a Duty to Act, which inheres in a Duty Holder and is externally dependent on a Right Holder. As any legal relation, a Right-Duty to an Action is created, modified or extinguished by an event (natural or social) relevant in the scope of that normative system. 


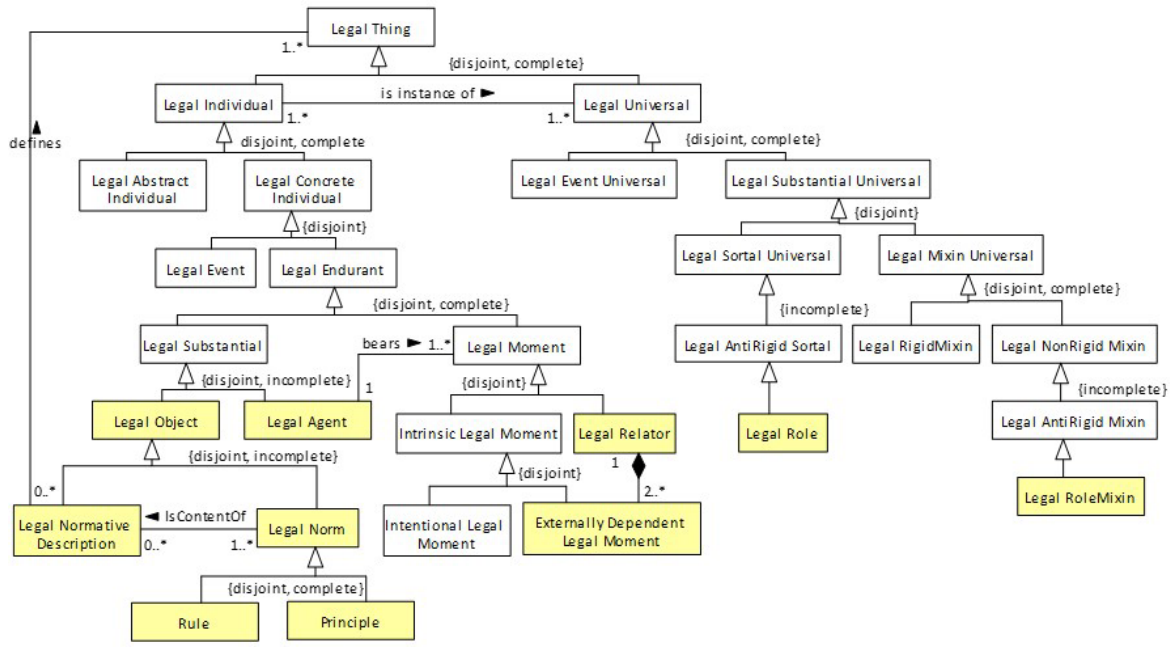

Figure 3. A Fragment of UFO-L

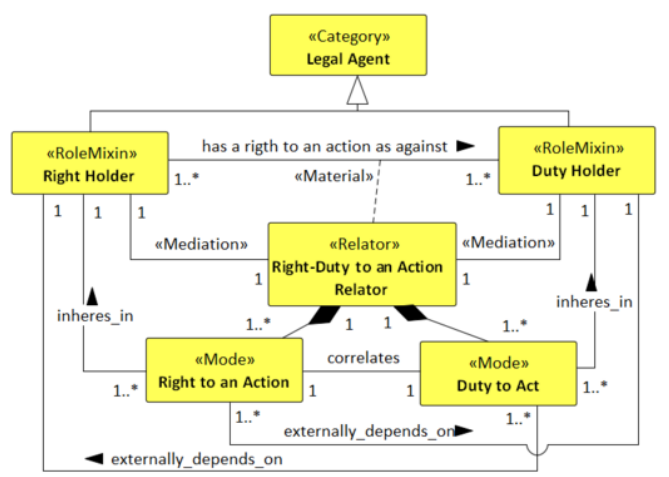

Figure 4. UFO-L: Right-Duty to an Action Legal Relator Pattern

\section{Case Study: The Dedier Case}

\subsection{Case Description}

This case (hereinafter called Dedier case) was selected from the database of the Court of Appeals of the State of Espírito Santo, in Brazil. It consists of an appeal against a decision given by the court in the first instance to a writ of mandamus ${ }^{4}$. In the sequel, we present a summary of this case:

Dedier, a civil police officer, public servant in probationary period $(P E)$, required a leave of absence for dealing with private affairs (LDPA), more specifically, a leave from

\footnotetext{
${ }^{4}$ Writ of mandamus, "writ of security" or mandamus in Brazilian judiciary system is a type of action used to protect either individual or collective rights against abuse of power or illegality of a public authority or the representative of a legal entity in charge of public attributions when there is a threat to a clear legal right. It is a very similar instrument to the "writ of mandamus" in the United States of America's legal system.
} 
his work so that he could attend a clerk training course at the National Academy of the Federal Police. This position as a trainee at the National Academy is considered a Public Position in itself. However, the Civil Police Chief of the State of Espírito Santo (PCES) denied his leave request based on the Complementary Law LC n.46/94, article 41 (hereafter LC 46/94) [27] that does not allow the granting of LDPA for public servants in probationary period. Dissatisfied with this decision, Dedier filed a writ of mandamus with a summary judgement injunction invoking the Brazilian constitutional principle of access to public positions prescribed in Article $5^{\circ}$ of Brazilian Constitution (hereafter CRFB/1988) [28] and the right to LDPA. The judge of the first instance denied summary judgement because he understood that, prima facie, the right to leave would not apply for servants on probationary period. Once more, discontented with the judge's decision, Dedier filed an appeal before the Court of Appeals of the State of Espirito Santo (TJES) (process number 24079009809). Justice 'ad quem' partially overturned the first instance judge's decision, in view of the fact that, in applying Alexy's Proportionality Postulate, he found that the most appropriate rule-principle was that which least violated the principles involved (principle of probationary period versus principle of access to a public positions and principle of due process of law).

\subsection{Brief Remarks}

As social relations become more complex, we find more and more cases that fall outside what is prescribed by our normative system, i.e., cases for which there are no legal rules to which the facts can be subsumed. In analysing these cases of omissions, we often observe that in their core, they also exhibit situations of collisions of constitutional rights (or collisions of principles in Alexy's theory). For instance, the principle of information can collide with the principle of privacy; the principle of public health with the principle of freedom of come and go. The analysis of merit in these cases is complex and encourages the use of legal theories that propose a model of weighting and balancing solutions as opposed to the model of subsumption of facts to general and abstract norms in a closed normative system. To support this analysis, we need a model that allows for reasoning about the law in case-by-case basis, with a different analysis of the effects of norms on positions and legal relations.

\section{An Ontological Analysis in LKIF-Core following Kelsen's Approach}

This section presents the decision in the Dedier case in the perspective of a decisionmaker who decides only based on the norms and rules at hand, as the first judge of this case. In the case under analysis, consider the fact $F_{D}$ : Dedier, a public official on probationary period at the Civil Police of the State of Espírito Santo, required a leave of absence for attendance of private interests. Thus, if the fact $F$ exists and a rule $R$ exists in the legal system, applicable to fact $F$, it is said that fact $F$ subsumes under the rule $R$. In the case of Dedier, fact $F_{D}$ subsumes under the rule LC46/94 as there is no exception in the legal rule prescribed. Therefore, Dedier does not have right to the required leave.

By modeling Dedier case in LKIF-core, the module NORM proposed in [13], allows (ALLOWS) situations that match the following description: 
thus, disallowing (DISALLOWS) descriptions that match the following situation (where being a tenured public servant is the complement-logical negation of - being a public servant on probationary period):

\section{PUBLIC_SERVANT_ON_LEAVE $\sqcap \neg$ TENURED_PUBLIC_SERVANT}

In other words, it is necessary that every PUBLIC_SERVANT_ON_LEAVE is a TENURED_PUBLIC_SERVANT:

\section{LDPA $\sqsubseteq$ allows only (PUBLIC_SERVANT_ON_LEAVE $\sqcap$ TENURED_PUBLIC_SERVANT)}

The specific aspects of the the Dedier case are not foreseen by the Brazilian normative system. That is, from the perspective of a closed normative system, there is no norm type in this system under which this case would naturally be subsumed with all its conflicting aspects. Thus, a possibility to a favorable decision to Dedier using this perspective would be the alter of LC $46 / 94$ by the Legislative process (i.e., the approval of a rule exception by the Parliament).

Similar to LKIF-core in terms of deontic operators, the CLO ontology implements the subsumption operation as a task of conformity checking, which, when applied to a case, it classifies the case as conforming to or not conforming to the norm. In these ontologies, the concept of conformity or nonconformity of the case to the norm is used together with the deontic operators (prohibition, permission and obligation) in monadic formulae. Conformity analysis is performed only in relation to the rule-principle to which the fact is subsumed and not to the whole set of rules-principles and principles that exist in the normative system.

In summary, in these ontologies and under the Kelsenian view, it is not possible to properly model the decision pronounced by the second judge of the case (the judge of the Appeal Court), since this view is only based on 1) legal rules of a closed normative system; and 2) a subsumption operation of fact to a given legal type.

\section{An Ontological Analysis in UFO-L following Alexy's Approach}

As previously discussed, following an Alexyan approach allows us to reason about the specificity of particular cases. In this particular case, we have a case of collision of principles. The collision is not observed as a collision of the rule-norm in their abstract form, but for the case of a particular individual, who playing different roles is entitled to different rights. To put it in a different way, the situation described by the combination of roles instantiated by the individual is not prescribed by that normative system (as it is often the case of complex systems in which individuals can play multiple independent roles). That is why this can be considered also as a case of normative omission.

For the Dedier case, an ontological analysis based in UFO-L allows us to identify a number of elements that are used in the decision-making process by the different legal agents involved in this case. These elements are identified in Tables 1, 2 and 3, and are explicitly represented and articulated in the remainder of this section. In particular, we model the several perspectives of the case by instantiating the Ontology Design Pattern of UFO-L introduced in Section 1 for the case of each legal relation and legal role identified. 


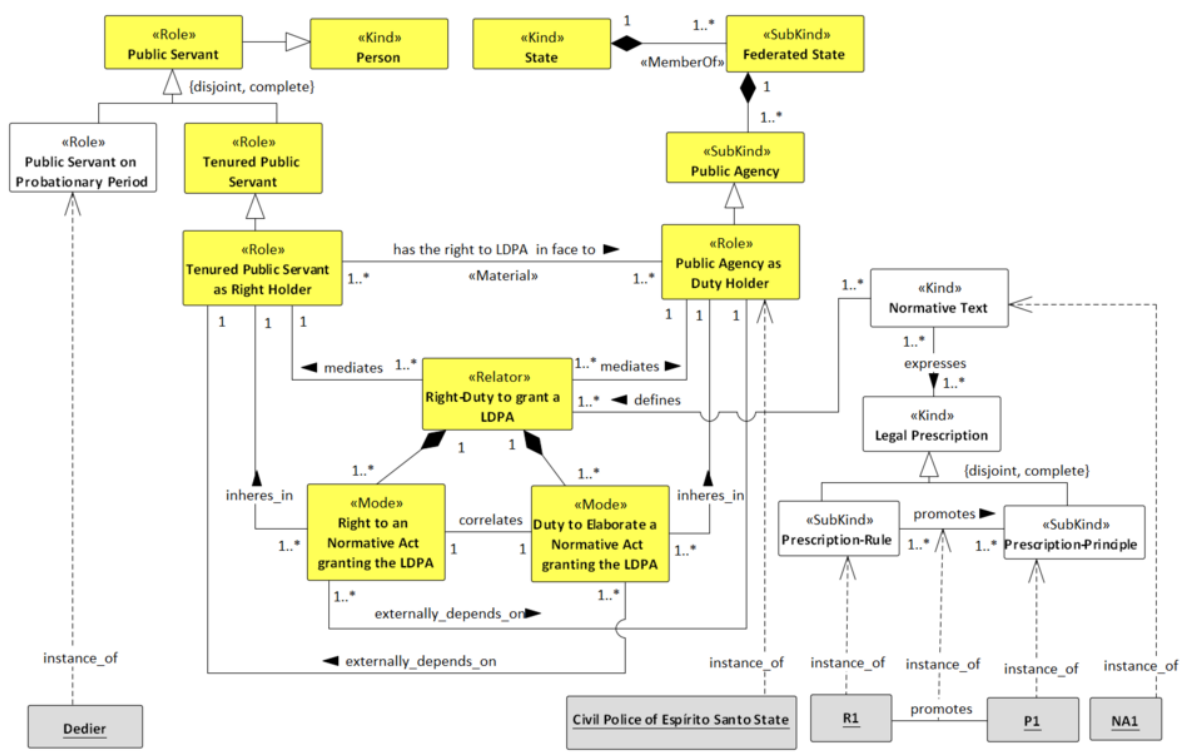

Figure 5. Perspective $_{1}$ modeled in UFO-L

Perspective $_{1}$ (Dedier does not not have the right to a LDPA): This perspective represents thesis ${ }_{1}$ (Table 1), i.e., the positions of the Chief of the Civil Police and of the first judge (judge ${ }_{1}$ ) of the case. As shown in Figure 5, the public servant Dedier is not an instance of Tenured Public Servant Right Holder and, as consequence, he is not entitled to the right to a leave of absence for dealing with private affairs (LDPA).

Table 1. Elements of the Decision-Making Process - Perspective 1

\begin{tabular}{|l|l|}
\hline Fact $\boldsymbol{F}$ & $\begin{array}{l}\text { Dedier, a public servant on probationary period at the Civil Police of the State of Espírito } \\
\text { Santo, applied for a leave of absence for dealing with private affairs (LDPA). }\end{array}$ \\
\hline Thesis ${ }_{1}$ & $\begin{array}{l}\text { Dedier is a public servant on probationary period and, thus, he does not have the right to } \\
\text { a LDPA. }\end{array}$ \\
\hline Principle $\mathbf{P}_{1}$ & $\begin{array}{l}\text { Constitutional Principle of probationary period seeks to allow for the evaluation of the } \\
\text { aptitude of a public servant to occupy a given public position. }\end{array}$ \\
\hline $\begin{array}{l}\text { Normative } \\
\text { Act } \mathbf{N A}_{1}\end{array}$ & $\begin{array}{l}\text { LC 46/94, art. 41: The types of leaves prescribed in art. 122, V and VIII will not be } \\
\text { granted to public servants } \text { on probationary period. }\end{array}$ \\
\hline Rule $\mathbf{R}_{1}$ & $\begin{array}{l}\text { Ought not } \text { (grant the types of leaves prescribed in art. 122, V and VIII to public servants } \\
\text { on probationary stage). } \\
\text { LC 46/94, art. 122, VIII and LC 46/94, art. 41 are adequate to promote the Constitutional } \\
\text { Principle P } .\end{array}$ \\
\hline $\begin{array}{l}\text { Legal } \text { Rela- } \\
\text { tion in } \mathbf{P}_{1}\end{array}$ & $\begin{array}{l}\text { There is no legal relationship between Dedier and the Civil Police Department of Espírito } \\
\text { Santo State in terms of granting a LDPA because Dedier is in a probationary stage. }\end{array}$ \\
\hline
\end{tabular}

Perspective $_{2}$ (Dedier has the right to a LDPA): This perspective represents Dedier's thesis (Table 2) and it is the basis of his appeal petition before the Appeal Court. In this scenario (Figure 6), we have the representation of other rights to which Dedier is entitled, namely, the Right to Non-Hindrance in Access to Public Positions as well as the Right to a Normative Action to have Access to Public Positions. The articulation of legal 
Table 2. Elements of the Decision-Making Process - Dedier's thesis

\begin{tabular}{|c|c|}
\hline Thesis $_{2}$ & $\begin{array}{l}\text { As a Brazilian citizen and having fulfilled the requirements established by law, the norm } \\
\text { that ensures access to public employment must stand out against an infra constitutional } \\
\text { norm colliding with this principle. }\end{array}$ \\
\hline Principle $\mathbf{P}_{2}$ & $\begin{array}{l}\text { Constitutional Principle of accessibility to public employment. Access to public employ- } \\
\text { ment is guaranteed to all Brazilians who meet the requirements established by law and } \\
\text { to foreigners, in accordance with the law. }\end{array}$ \\
\hline $\begin{array}{l}\text { Normative } \\
\text { Act } \mathbf{N A}_{2}\end{array}$ & Brazilian Constitution, art. 37, I. \\
\hline Rule $\mathbf{R}_{2}$ & $\begin{array}{l}\text { Ought to guarantee the access to public position and Ought not hinder access to the } \\
\text { public position. Brazilian Constitution, art. } 37, \mathrm{I} \text { is adequate to promote Principle } \mathrm{P}_{2} \text {. }\end{array}$ \\
\hline $\begin{array}{l}\text { Legal Rela- } \\
\text { tion in } \mathbf{P}_{2}\end{array}$ & $\begin{array}{l}\text { Every Brazilian has the right that the State guarantees access to public employment, once } \\
\text { the candidates fulfill the requirements established by law. Thus, there is a relationship } \\
\text { between Dedier and PC-ES Dept. in terms of rights to a LDPA. }\end{array}$ \\
\hline
\end{tabular}

scenarios reflects the judge's consideration of a possible "tension" between the principles involved. In this case, we have: principle $\mathrm{P}_{1}$ that articulates that a public servant on probationary period should not be entitled to leaves of absence (5); but we also have principle $\mathrm{P}_{2}$ (defined by constitutional rule $\mathrm{R}_{2}$ ) guaranteeing access to public positions. It is important to highlight that there is no conflict in the norm-rules themselves but in norm-principles in this case. The collision exists because, in this concrete case, we have the same individual playing different roles and, hence, being entitled to different rights based on different principles. In other words, the conflict arises because a decision that conforms to one of the roles might hurt rights entailed by other roles (in other relations).

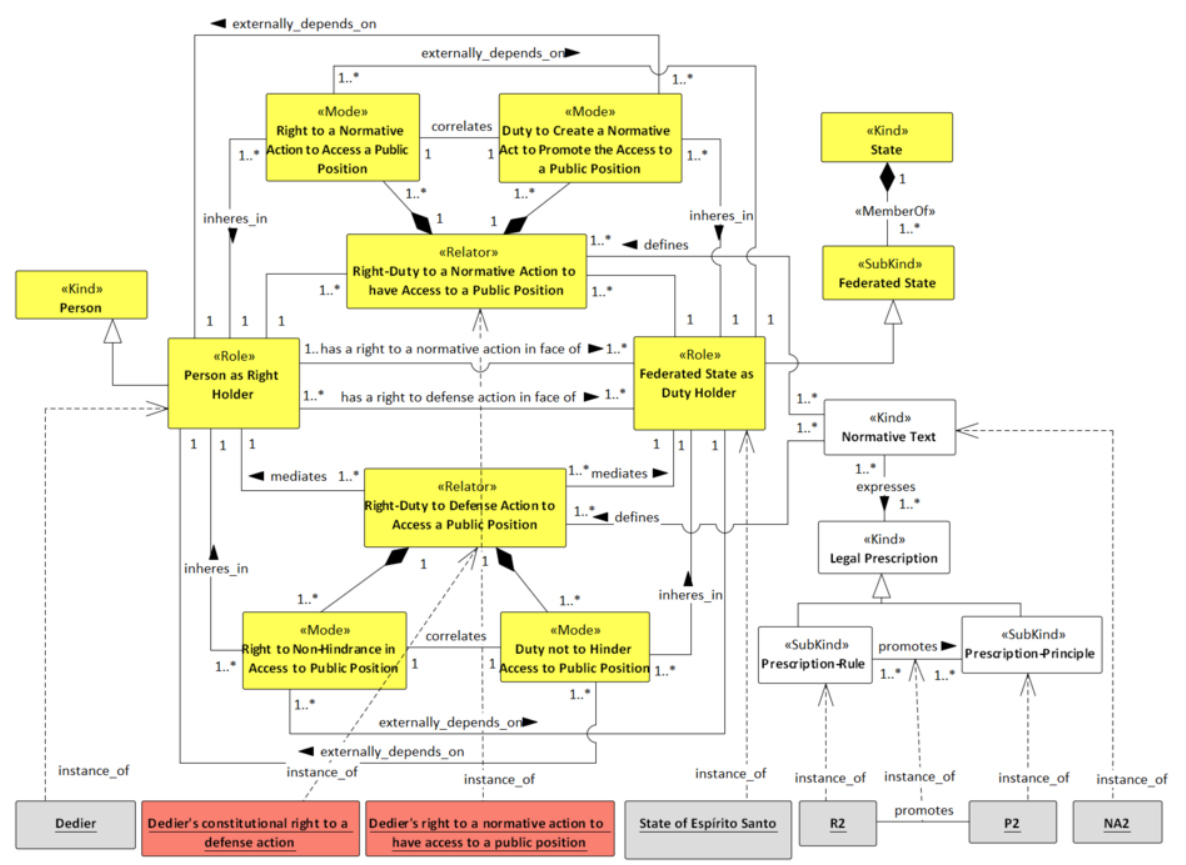

Figure 6. Perspective 2 modeled in UFO-L 
Perspective $_{3}$ (Reasoning of Appeal Court's Justice): Figure 7 depicts the representation of a reasoning fragment of the Appeal Court's justice (judge ${ }_{2}$ ) described in Table 3. It emerges from the existence of the principle of due process of law prescribed in Brazilian Constitution, art. 5, LIV [28] inherent to all procedural legal relations, as well as from the principle of substantive due process of law, stemming from the former. By the principle of formal due process of law, no one shall be deprived of liberty or property without a due process, and also, every act emanating from a judging authority shall observe the legal procedure to be valid and effective. The consequence of this principle is the principle of the substantive due process, that guarantees not only the formality of the process (external character), but also requires proportionality and the reasonableness of the decisions. Therefore, the principle $\mathrm{P}_{3}$ promoted by rule $\mathrm{R}_{3}$ is a principle that regulates every legal (and extra-judicial) procedural relation and can be raised both by the parties and judges, as occurred in the Dedier Case.

Table 3. Elements of the Decision-Making Process - Judge's reasoning

\begin{tabular}{|c|c|}
\hline Situation $_{1}$ & Collision of Constitutional Principles $\left(\mathrm{P}_{1}\right.$ versus $\left.\mathrm{P}_{2}\right)$ \\
\hline Principle $\mathbf{P}_{3}$ & $\begin{array}{l}\text { Constitutional principle of substantive due process of law, express in Brazilian Constitu- } \\
\text { tion, art. } 5^{\circ} \text {, LIV (Rule } R_{3} \text { ). }\end{array}$ \\
\hline $\begin{array}{l}\text { Legal Rela- } \\
\text { tion in } P_{3}\end{array}$ & $\begin{array}{l}\text { Every person has the right to the guarantee to substantive due process of law before } \\
\text { Brazilian State. }\end{array}$ \\
\hline Rule RC & $\begin{array}{l}\text { Concrete legal norm introduced by the second judge of the case: the probationary stage } \\
\text { is interrupted during the intended leave, but the full realization of the principle } \mathrm{P}_{1} \text { is } \\
\text { possible after the end of the leave without violation of the principles } \mathrm{P}_{2} \text { and } \mathrm{P}_{3} \text {. }\end{array}$ \\
\hline $\begin{array}{l}\text { Reasoning } \\
\text { of Judge }_{2}\end{array}$ & $\begin{array}{l}\text { Rule } \mathrm{R}_{1} \text { blocks the fulfillment of principle } \mathrm{P}_{2} \text {. Rule } \mathrm{R}_{1} \text { is unconstitutional in this case, } \\
\text { because it violates the constitutional principle of substantive due process of law }\left(\mathrm{P}_{3}\right) \text {. }\end{array}$ \\
\hline $\begin{array}{l}\text { Judge }_{2} \text { 's } \\
\text { Ruling }\end{array}$ & Once rule $\mathrm{RC}$ is prescribed, fact $\mathrm{F}$ must subsumed under rule $\mathrm{RC}$ and not rule $\mathrm{R}_{1}$. \\
\hline $\begin{array}{l}\text { Legal Rela- } \\
\text { tion in RC }\end{array}$ & $\begin{array}{l}\text { There is a new legal relationship between Dedier and the PC-ES Dept. once the public } \\
\text { servant has the right to LDPA before the PC-ES Dept. according to rule RC. }\end{array}$ \\
\hline
\end{tabular}

$\boldsymbol{J u d g e}_{2}$ 's Ruling - the analysis of perspectives 1, 2 and 3 reveals that the rule in LC $46 / 94$ ensures the constitutional rule that promotes the principle of probationary stage $\left(\mathrm{P}_{1}\right)$, but conflicts with the constitutional rules that promote the principles of access to public positions $\left(\mathrm{P}_{2}\right)$ and substantive due process of law $\left(\mathrm{P}_{3}\right)$. Therefore, judge $\mathrm{e}_{2}$ deciding on the appeal of this case understood that it is possible to consider a new ruling RC (Rule $\mathrm{RC}$ ) that ensures a minor violation of the principles involved (Figure 8).

What we have modeled in Figure 5 can be seen as a legal domain ontology module focused on the rights involved in a LDPA. What we have in Figure 8, in contrast, can be seen as an extension to this module with a specialization of the role Public servant on Probationary Stage. In this manner, UFO-L allows the representation of several existing perspectives in a case, according to the existence of legal relations and their relation to rules and principles. Furthermore, as we have seen in this case, it is possible to model in UFO-L both conflict of rules and collision of principles since it permits the judge to insert prescriptions in the normative system by means of judicial decisions in concrete cases. 


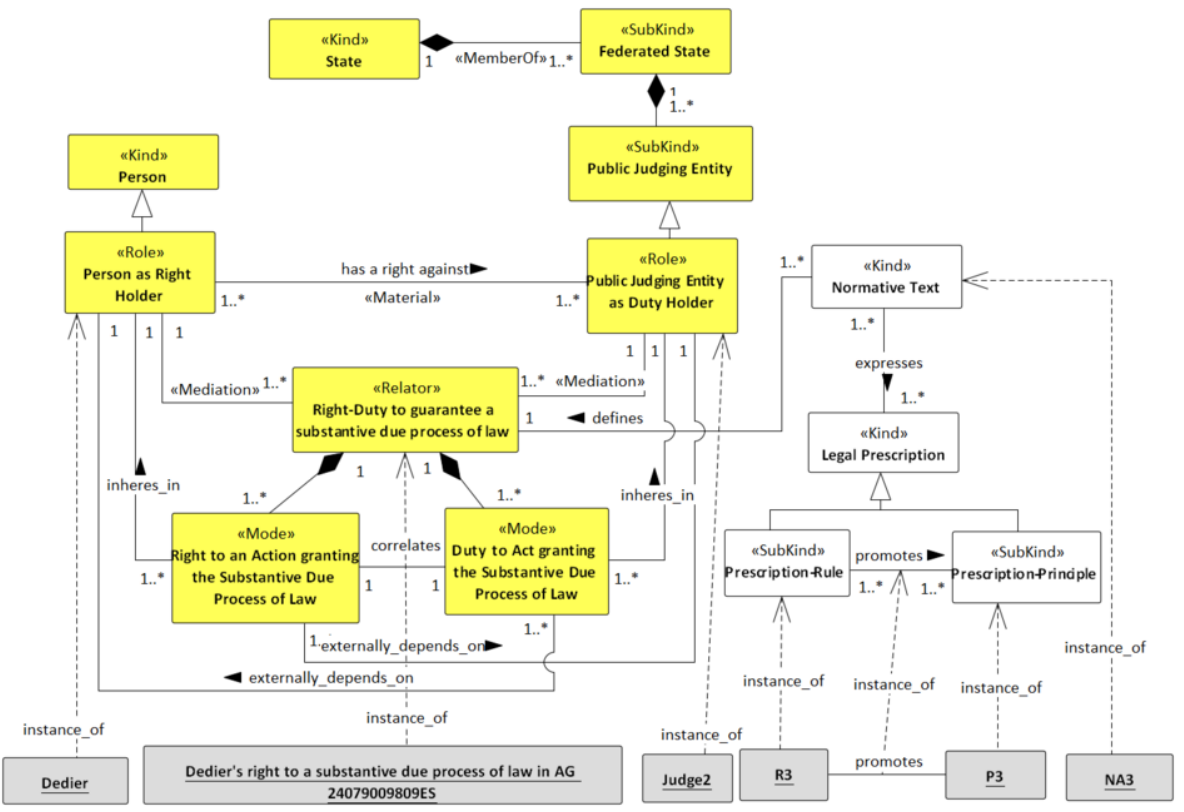

Figure 7. Perspective 3 modeled in UFO-L: judge 2 's reasoning fragment

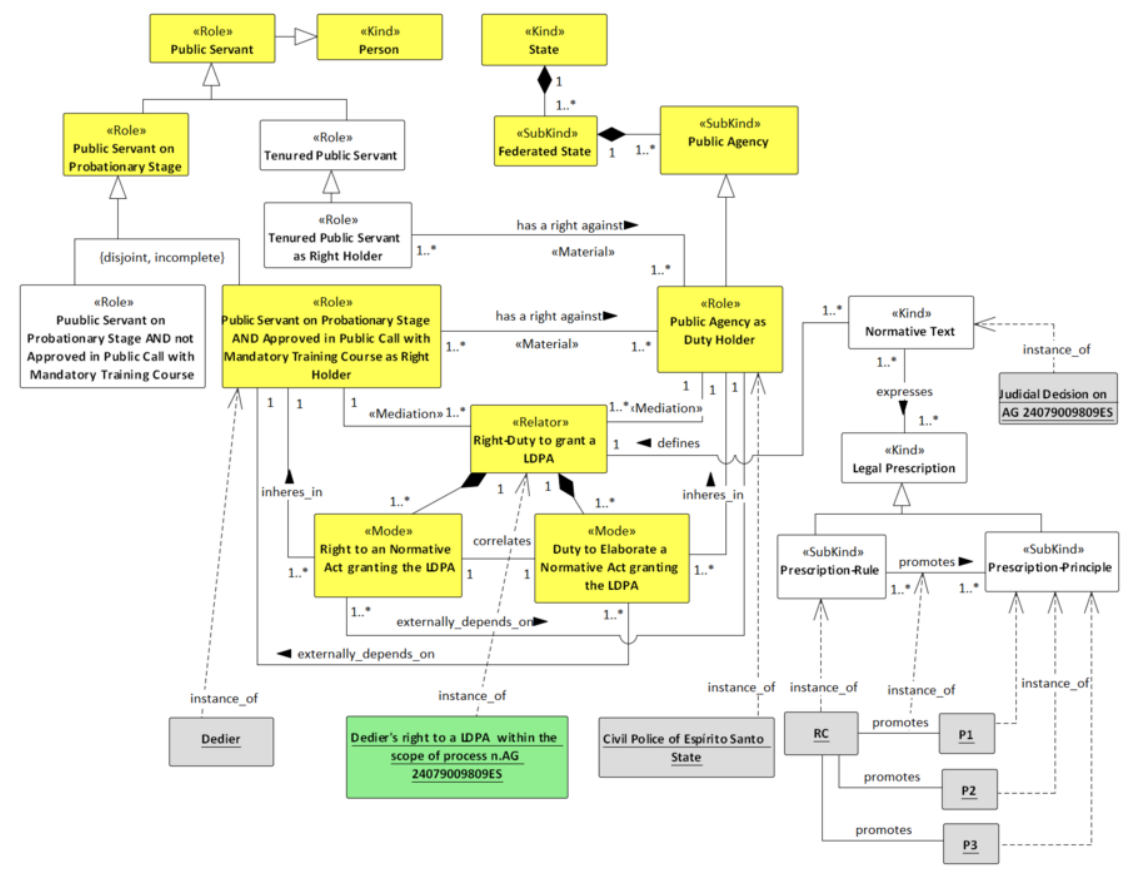

Figure 8. Perspective $_{3}$ modeled in UFO-L: judge 2 's ruling 


\section{Final Considerations}

In this paper, we conducted an ontological analyses with the support offered by two Legal Core Ontologies (LKIF-Core and UFO-L) for Judicial Decision-Making. We chose these ontologies because they represent two classes of Legal Theories, namely, Kelsen's Pure Theory of the Law (LKIF-Core) and Alexy's Theory of Constitutional Rights (UFO-L). Our goal is to demonstrate how these theories embedded in the design of these ontologies influence their ability to offer informative insights in complex cases of decisionmaking in which we have normative omissions and collisions of principles. We do this by employing a selected real case.

Normative omissions and collision of principles are not logically connected but frequently appear together in real cases. The underlying phenomenon here is the following. In legal positivism (Kelsen), the law is described as a system of relations between general (universal) norms. However, in complex legal settings, we often have cases in which, despite the absence of conflict between general norms, we have conflicts of legal positions (e.g., rights) inhering in specific individuals. In other words, the collision emerges because the same individual can play different roles (and each of which can entail conflicting positions). The collision of principles in these cases can be considered a case of omission because the rules that would otherwise govern that particular individual case (i.e., under which that case could be subsumed) will always be missing in practice in these cases. Since no sufficiently complex normative system (defined at the level of general norms) can be guaranteed to be complete (i.e., accounting for all particular situations), judicial decision-making should be supported by a framework that allows for reasoning in terms of individuals, the roles they play, the legal positions they bear and the relations they establish with other legal agents. As our analysis shows, Alexy's theory and the UFO-L ontology allows for a much more suitable, detailed and informative analysis of such cases, which is required to capture the semantics of legal decisions such as those discussed in the Dedier case.

A future work will be to perform an additional empirical study with a relevant sample of cases with collisions of principles to verify the degree to which UFO-L helps in bringing more clarity and understanding of the theses in a judicial case.

Acknowledgement. João Paulo A. Almeida is funded by the Brazilian Research Funding Agencies CNPq (grant number 312123/2017-5).

\section{References}

[1] Capurso TJ. How judges judge: Theories on judicial decision making. University of Baltimore Law Forum. 1999;29:5.

[2] Griffo C, Almeida JPA, Guizzardi G. A Systematic Mapping of the Literature on Legal Core Ontologies. In: Proc. Brazilian Seminar on Ontologies (ONTOBRAS 2015). vol. 1442 of CEUR Workshop Proceedings; 2015. p. 1-12.

[3] Rinke H, Joost B, Marcello DB, Alexander B. LKIF Core: Principled Ontology Development for the Legal Domain. Frontiers in Artificial Intelligence and Applications. 2009;188: Law, Ontologies and the Semantic Web:21-52.

[4] Griffo C, Almeida JPA, Guizzardi G. Towards a Legal Core Ontology based on Alexy's Theory of Fundamental Rights. MWAIL, ICAIL. 2015;. 
[5] Ajani G, Boella G, Lesmo L, et al. Multilevel Legal Ontologies. In: LNCS. vol. 6036. Springer Berlin Heidelberg; 2010. p. 136-154.

[6] Caralt NC. Modelling Legal Knowledge through Ontologies. OPJK: the Ontology of Professional Judicial Knowledge [PhD thesis]. UAB, Spain. Barcelona; 2008.

[7] Valente A, Breuker J. Towards Principled Core Ontologies. Proc Tenth Work Knowl Acquis Knowledge-Based Syst. 1996;

[8] Kralingen RV, Oskamp E, Reurings E. Norm Frames in the Representation of Laws. In: Leg. Knowl. Based Syst. JURIX 93.; 1993. p. 11-22.

[9] Valente A. Legal Knowledge Engineering; A Modelling Approach. Amsterdam: IOS Press; 1995.

[10] Shaheed J, Yip A, Cunningham J. A Top-Level Language-Biased Legal Ontology. In: ICAIL Work. Leg. Ontol. Artif. Intell. Tech.; 2005. .

[11] Gangemi A, Sagri MT, Tiscornia D. A Constructive Framework for Legal Ontologies. In: Law Semant. Web. Berlin: Springer Berlin Heidelberg; 2004. p. 97-124.

[12] Breuker J, Hoekstra R, Boer A, van den Berg K, Sartor G, Rubino R, et al. OWL Ontology of Basic Legal Concepts (LKIF-Core). University of Amsterdam; 2007.

[13] Hoekstra R, Breuker J, Di Bello M, Boer A. The LKIF Core Ontology of Basic Legal Concepts. In: CEUR Work. Proc.. vol. 321; 2007. p. 43-63.

[14] Kelsen H. Pure Theory of Law. Berkeley, CA: University of California Press; 1934.

[15] Green L, Adams T. Legal Positivism. In: The Stanford Encyclopedia of Philosophy. Winter 2019 ed. Metaphysics Research Lab, Stanford University; 2019. .

[16] Brasil. Código Penal. 45th ed. São Paulo: Saraiva; 2007.

[17] Boer A, Winkels R, Vitali F. Metalex XML and the legal knowledge interchange format. In: Computable models of the law. Springer; 2008. p. 21-41.

[18] Alexy R. A Theory of Constitutional Rights. Oxford: Oxford Univ. Press; 2009.

[19] Griffo C, Almeida JPA, Guizzardi G, Nardi JC. From an Ontology of Service Contracts to Contract Modeling in Enterprise Architecture. In: 2017 IEEE 21st International EDOC Conference; 2017. p. 40-49.

[20] Griffo C, Almeida JPA, Guizzardi G. Conceptual Modeling of Legal Relations. In: Int. Conf. Concept. Model. Xi'an, China: Springer; 2018. p. 169-183.

[21] Guizzardi G. Agent Roles, Qua Individuals and The Counting Problem. In: Int. Work. Softw. Eng. Large-Scale Multi-agent Syst.; 2005. p. 143-160.

[22] Guizzardi R, Perini A, Susi A. Aligning goal and decision modeling. In: CAiSE Forum 2018, LNBIP. vol. 317. Springer International Publishing; 2018. p. 105-113.

[23] Benevides AB, Bourguet JR, Guizzardi G, Penãloza R, Almeida JPA. Representing a reference foundational ontology of events in SROIQ. Applied Ontology. 2019 Aug;14(3):293-334. Available from: http://doi .org/10.3233/A0-190214.

[24] Guarino N, Guizzardi G. "We need to discuss the Relationship": Revisiting Relationships as Modeling Constructs. In: 27th Int. Conf. CAiSE 2015 Proc. Sweden: Springer International Publishing; 2015. p. 279-294.

[25] Griffo C, Almeida JPA, Guizzardi G, Nardi JC. Service contract modeling in enterprise architecture: An ontology-based approach. Inf Syst. 2019;p. 101454.

[26] Griffo C. UFO-L: Uma Ontologia Núcleo de Aspectos Jurídicos Construída sob a Perspectiva das Relações Jurídicas [PhD Thesis]. Ufes; 2018.

[27] Espírito Santo (Estado). Lei Complementar n. 46/94. Regime Jurídico dos Servidores Públicos do Estado do Espírito Santo. Vitória, ES: DOES; 1994.

[28] Brasil. Constituição da República Federativa do Brasil. Brasília: Senado Federal; 1988. 